\title{
Chronic Hepatitis C Treatment in Patients with Drug Injection History: Findings of the INTEGRATE Prospective, Observational Study
}

\author{
Geert Robaeys · Stefan Christensen - Damien Lucidarme • Amber Arain • \\ Philip Bruggmann · Jan Kunkel · Sofia Keim • Martin Jäkel • \\ Ralph DeMasi · Chris Liu · Isabelle Lonjon-Domanec · Graham R. Foster
}

Received: December 15, 2016/Published online: May 5, 2017

(C) The Author(s) 2017. This article is an open access publication

\section{ABSTRACT}

Introduction: People who inject drugs represent an under-treated chronic hepatitis $C$ virus (HCV)-infected patient population.

Methods: INTEGRATE was a prospective, observational study investigating the effectiveness, safety, and adherence in routine clinical practice to telaprevir in combination with peg-interferon and ribavirin (Peg-IFN/RBV) in patients with history of injecting drug use chronically infected with genotype $1 \mathrm{HCV}$.

Enhanced content To view enhanced content for this article go to http://www.medengine.com/Redeem/ 9A18F0602C81E0BE.

\section{G. Robaeys $(\bowtie) \cdot$ A. Arain}

Faculty of Medicine and Life Sciences, University Hasselt Campus Diepenbeek, Diepenbeek, Belgium e-mail: Geert.Robaeys@ZOL.BE

\section{G. Robaeys · A. Arain}

Department of Gastroenterology and Hepatology, Ziekenhuis Oost Limburg, Genk, Belgium

\section{G. Robaeys}

Department of Hepatology UZ Leuven, Leuven, Belgium

\section{S. Christensen}

Infectious Diseases, Center for Interdisciplinary

Medicine (CIM), Münster, Germany

D. Lucidarme

Universite Nord de France, 59000 Lille, France
Results: A total of 46 patients were enrolled and included in the intent-to-treat (ITT) population. Among heroin and/or cocaine users $(n=37 ; 80 \%), 22 \%$ reported use in the past month; $74 \%(34 / 46)$ of patients were on opioid substitution therapy in the pre-treatment phase, and 43\% (20/46) discontinued HCV treatment prematurely. Sustained virologic response rate was $54 \%(25 / 46)$ in the ITT population and $74 \%$ $(25 / 34)$ in the per protocol (evaluable-for-effectiveness) population. The main reason for failure in the ITT analysis was loss to follow-up $(n=8 ; 17 \%)$. Adverse events occurred in $91 \%$ $(42 / 46)$ of patients. Mean patient-reported adherence to study drugs was $>89 \%$ at Week 4 , Week 12 and end of treatment.

\author{
D. Lucidarme \\ UCLille, 59000 Lille, France \\ D. Lucidarme \\ Service de Pathologie Digestive, Centre Hospitalier \\ Saint Philibert, 115, rue du Grand But, \\ 59462 Lomme Cedex, France \\ P. Bruggmann \\ Arud Centres for Addiction Medicine, Zurich, \\ Switzerland \\ J. Kunkel · G. R. Foster \\ Hepatology Unit, Queen Mary University of \\ London, London, UK \\ S. Keim \\ Janssen-Cilag, Barcarena, Portugal
}


Conclusion: Despite a high rate of treatment discontinuation (including loss to follow-up), self-reported adherence to treatment was good and virologic cure rates were similar to those reported in large real-world cohorts. Our findings suggest that people with a history of injecting drug use should be considered for treatment of chronic HCV infection, and highlight the need for improvements in patient support to boost retention in care and, in turn, help to prevent reinfection and transmission.

Clinical trial registration: Clinicaltrials.gov identifier, NCT01980290.

Funding: Janssen Pharmaceuticals.

Keywords: HCV; Injection drug users; Opioid substitution therapy; PWID; Retention in care; Telaprevir

\section{INTRODUCTION}

Globally, 130-150 million people are estimated to be chronically infected with hepatitis $C$ virus (HCV) [1]. In developed countries, injecting drug use typically accounts for $20-40 \%$ of HCV infections [2]; the prevalence of hepatitis C antibodies in people who inject drugs (PWIDs) is estimated at $67 \%$ worldwide [3]. High-risk behaviors among PWIDs (sharing needles, syringes, and other equipment) are common, and are responsible for a high proportion of ongoing transmission in many regions. Among current PWIDs in Europe, median incidence of community-acquired HCV infection is approximately 26 infections per 100 person-years [3]. Furthermore, rates of reinfection following viral clearance are estimated to be between 1.8 and 46.7 cases per 100 person-years [4]. Therefore, comprehensive implementation of harm reduction strategies, together with broad access

M. Jäkel

Janssen-Cilag B.V, Breda, The Netherlands

R. DeMasi · C. Liu

Janssen Research and Development LLC, Titusville, USA

I. Lonjon-Domanec

Janssen-Cilag, Paris, France to treatment for this patient population, have the potential to play a key role in the elimination of HCV [4].

However, despite modeling studies indicating the utility of effective treatment in preventing $\mathrm{HCV}$ transmission among PWIDs [5], reluctance on the part of clinicians to treat this vulnerable population means that treatment rates have historically been suboptimal [6].

Studies using dual peg-interferon and ribavirin (Peg-IFN/RBV) therapy in PWID have demonstrated high adherence $[7,8]$, highlighting the potential for such patients to sustain a complex regimen over a long duration. However, challenges associated with retention in care, particularly following treatment completion, mean that the full benefits of treatment may not be realized or reflected in reported data.

In 2013, when our study was designed, there were no data available in PWIDs treated with the first-generation direct-acting antivirals (DAAs), telaprevir and boceprevir. These two drugs, in combination with Peg-IFN and RBV, increased virologic cure rates but at the expense of additional toxicity compared to Peg-IFN and RBV alone $[9,10]$. The more recent introduction of highly effective and well-tolerated IFN-free DAA combinations for HCV treatment has made HCV elimination in PWIDs a plausible near-future scenario $[11,12]$. Improved understanding of considerations around adherence to therapy and retention in care among this challenging population could lead to improved patient outcomes and important public health benefits. The aims of this study were to evaluate the effectiveness, safety, and adherence to telaprevir combined with Peg-IFN and ribavirin in patients with a history of injecting drug use and who were chronically infected with genotype 1 (GT1) HCV.

\section{METHODS}

\section{Design and Eligibility Criteria}

INTEGRATE was a prospective, multicenter, non-interventional, single-arm study of telaprevir with Peg-IFN/RBV in adult patients 
chronically infected with HCV GT1 who had a history of injecting drug use and any fibrosis stage including compensated cirrhosis. Patients had recent documentation (within 18 months) of the degree of liver fibrosis (METAVIR F0-F4; Ishak 0-6), assessed by liver biopsy or non-invasive test (e.g., FibroTest, Fibroscan) $[13,14]$. Patients were receiving opioid substitution therapy (OST; e.g., methadone or buprenorphine) and/or were followed in an addiction center/program. Patients were treatment-naïve or prior relapsers to IFN (pegylated or not) and RBV therapy; patients with prior history of DAA therapy were ineligible. In addition, patients with decompensated liver disease, active hepatitis B infection, HIV coinfection, or infection with HCV other than GT1 were excluded from the study, as were patients with contraindications to telaprevir, Peg-IFN or RBV.

\section{Setting}

The study was conducted from 13 May 2013 to 9 February 2015 at 18 sites in 6 countries: Belgium (6 sites), France (3 sites), Germany (4 sites), Netherlands (1 site), Switzerland (1 site), and Kingdom (3 sites). Participating physicians offered enrollment in this study to all eligible patients at their site in whom they planned to initiate therapy with telaprevir and Peg-IFN/ RBV.

The study was reviewed and approved by Independent Ethics Committees and conducted in accordance with the Helsinki Declaration of 1964, as revised in 2008 and 2013, and Good Clinical Practice guidelines. All patients provided written, informed consent prior to the start of the study (clinicaltrials.gov NCT01980290).

\section{Procedures}

Due to the non-interventional nature of the study, patient care and treatment followed local standard as well as HCV drug labels. Patients received telaprevir with Peg-IFN/RBV for 12 weeks, followed by either 12 or 36 weeks of Peg-IFN/RBV alone. Study drugs were not provided by the sponsor.
Prospective data were recorded at six time points for each patient (corresponding to routine care visits): inclusion, and at the patient's routine care visit closest to Weeks 4, 12, 24, end-of-treatment, and end-of-follow-up (approximately 12 weeks after end-of-treatment). No additional blood, urine, or other biological samples were required, and no additional investigations, beyond the routine clinical management of the patient, were performed.

\section{Objectives}

The pre-defined primary objective was to evaluate effectiveness based on sustained virologic response, defined as plasma HCV RNA level $<25 \mathrm{IU} / \mathrm{mL} 12$ weeks after last dose of study medication (SVR12). No formal hypothesis testing was performed in association with this primary objective owing to the non-comparative design of the study; inclusion of a comparator arm was deemed unethical.

Plasma HCV RNA was quantified using locally available assays such as the Roche High Pure COBAS ${ }^{\circledR}$ TaqMan $^{\circledR} 2.0$ or Abbott RealTime $\mathrm{HCV}$ assays. The lower limit of quantification was, or was imputed to be, $25 \mathrm{IU} / \mathrm{mL}$ for all assays used.

Efficacy was assessed in the intent-to-treat (ITT) and per protocol evaluable-for-effectiveness (EE) populations. The ITT population comprised all patients who received at least one dose of telaprevir and had $\geq 1$ post-baseline efficacy or safety assessment, while the EE population excluded patients with major protocol deviations plausibly affecting effectiveness, patients lost to follow-up and patients who completed the study but had missing HCV RNA at the SVR12 timepoint.

Secondary objectives included assessment of tolerability, safety, and adherence. Adherence was assessed using the self-reported, validated M-MASRI questionnaire [15]; assessment of pill/ vial counts was also included in the protocol. For the M-MASRI questionnaire, a horizontal visual analogue scale was used to generate a self-rated adherence measure (\% of doses received/total) for each of Peg-IFN, RBV and telaprevir. Excessive alcohol consumption was 
evaluated using the self-reported alcohol use disorders identification test (AUDIT) developed by the World Health Organization [16, 17].

\section{Statistical Methods}

Based on an expected response rate of $60 \%$ with the telaprevir-based regimen, it was calculated (based on exact binomial distribution and using the Clopper-Pearson formula) that a sample size of 80 evaluable patients would give a 2 -sided 95\% confidence interval extending 11\% above and below the expected observed response rate of $60 \%$. To allow for up to $30 \%$ of patients to have non-evaluable data (i.e., as-treated or observed analyses do not impute missing data) for the primary virologic endpoint, enrollment of 115 patients was planned.

\section{RESULTS}

A total of 49 adult patients with a history of injection drug use and chronic HCV GT1 infection were enrolled in the study. Enrollment was lower than expected due to alternative treatments becoming available in the participating countries. Of the 49 patients, 46 had post-baseline assessments and were included in the ITT analysis (Fig. 1; Table 1). All ITT

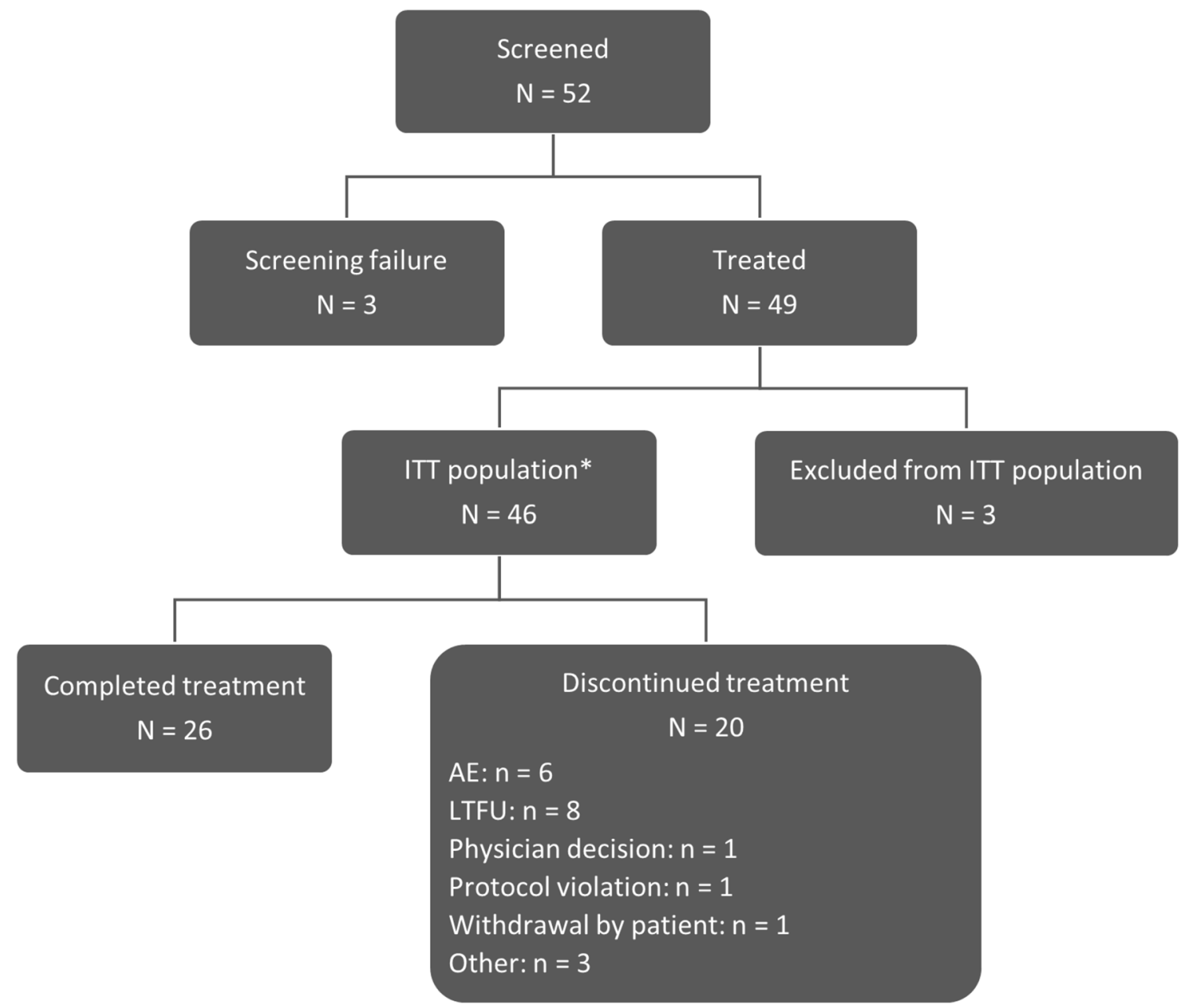

Fig. 1 Patient disposition. Asterisk ITT population is defined as all patients treated with telaprevir and having at least one post-baseline effectiveness or safety assessment.
Of the 49 patients who were treated, 46 had post-baseline assessments and were included in the ITT population. $A E$ adverse event, ITT intent-to-treat, $L T F U$ lost to follow-up 
Table 1 Baseline demographics and disease characteristics

\begin{tabular}{|c|c|c|c|}
\hline & $\begin{array}{l}\text { Treatment naïve } \\
(n=43)\end{array}$ & $\begin{array}{l}\text { Prior relapsers } \\
(n=3)\end{array}$ & $\begin{array}{l}\text { Total } \\
(n=46)\end{array}$ \\
\hline Median age, years (range) & $43(28-57)$ & $47(44-56)$ & $44(28-57)$ \\
\hline Age $\leq 45$ years, $n(\%)$ & $27(63)$ & $1(33)$ & $28(61)$ \\
\hline Caucasian, $n(\%)$ & $39(91)$ & $3(100)$ & $42(91)$ \\
\hline Male, $n(\%)$ & $37(86)$ & $3(100)$ & $40(87)$ \\
\hline \multicolumn{4}{|l|}{ Body mass index $\left(\mathrm{kg} / \mathrm{m}^{2}\right)$} \\
\hline Median (range) & $25(17-36)$ & $26(22-27)$ & $25(17-36)$ \\
\hline \multicolumn{4}{|l|}{ HCV subtype, $n$ (\%) } \\
\hline $1 \mathrm{a}$ & $34(79)$ & $3(100)$ & $37(80)$ \\
\hline $1 b$ & $7(16)$ & 0 & $7(15)$ \\
\hline Other (unspecified) & $2(5)$ & 0 & $2(4)$ \\
\hline \multicolumn{4}{|l|}{ Fibrosis stage, $n(\%)$} \\
\hline F0-1 & $15(35)$ & $1(33)$ & $16(35)$ \\
\hline F2 & $7(16)$ & 0 & $7(15)$ \\
\hline F3 & $4(9)$ & $1(33)$ & $5(11)$ \\
\hline F4 & $7(16)$ & 0 & $7(15)$ \\
\hline Unknown & $10(23)$ & $1(33)$ & $11(24)$ \\
\hline Baseline VL $\geq 800,000 \mathrm{IU} / \mathrm{mL}, n(\%)$ & $26(61)$ & $2(67)$ & $28(61)$ \\
\hline Patients on OST during pre-treatment phase, $n(\%)$ & $31(72)$ & $3(100)$ & $34(74)$ \\
\hline Methadone $^{\mathrm{a}}$ & $25(58)$ & $2(67)$ & $27(59)$ \\
\hline Buprenorphine $\mathrm{b}^{\mathrm{b}}$ & $6(14)$ & $1(33)$ & $7(15)$ \\
\hline Patients on OST during treatment phase, $n(\%)$ & $39(91)$ & $3(100)$ & $42(91)$ \\
\hline Methadone $^{a}$ & $30(70)$ & $2(67)$ & $32(70)$ \\
\hline Buprenorphine $^{\mathrm{b}}$ & $9(21)$ & $1(33)$ & $10(22)$ \\
\hline Heroin and/or cocaine use, $n(\%)$ & $35(81)$ & $2(67)$ & $37(80)$ \\
\hline Crack cocaine use, $n(\%)$ & $3(7)$ & 0 & $3(7)$ \\
\hline Methamphetamine use, $n(\%)$ & $2(5)$ & 0 & $2(4)$ \\
\hline Morphine or other opioids use, $n$ (\%) & $1(2)$ & 0 & $1(2)$ \\
\hline Last time heroin and/or cocaine used, $n$ & 35 & 2 & 37 \\
\hline Within the last month, $n(\%)$ & $8(23)$ & 0 & $8(22)$ \\
\hline $1-6$ months ago, $n(\%)$ & $3(9)$ & 0 & $3(8)$ \\
\hline More than 6 months, $n(\%)$ & $24(69)$ & $2(100)$ & $26(70)$ \\
\hline Psychiatric comorbidity, active (any), $n$ (\%) & $16(37)$ & $1(33)$ & $17(37)$ \\
\hline
\end{tabular}


Table 1 continued

\begin{tabular}{|c|c|c|c|}
\hline & $\begin{array}{l}\text { Treatment naïve } \\
(n=43)\end{array}$ & $\begin{array}{l}\text { Prior relapsers } \\
(n=3)\end{array}$ & $\begin{array}{l}\text { Total } \\
(n=46)\end{array}$ \\
\hline Depression & $9(21)$ & $1(33)$ & $10(22)$ \\
\hline Anxiety & $6(14)$ & 0 & $6(13)$ \\
\hline Psychosis, schizophrenia & $2(5)$ & 0 & $2(4)$ \\
\hline Patients using concomitant psychiatric therapies, $n(\%)$ & $18(42)$ & 0 & $18(39)$ \\
\hline Benzodiazepine derivatives & $13(30)$ & 0 & $13(28)$ \\
\hline Other antidepressants & $12(28)$ & 0 & $12(26)$ \\
\hline Other anxiolytics & $1(2)$ & 0 & $1(2)$ \\
\hline $\begin{array}{l}\text { Alcohol use disorders identification test (AUDIT) score at } \\
\text { baseline, } n\end{array}$ & 34 & 2 & 36 \\
\hline$\geq 8^{\mathrm{c}}, n(\%)$ & $14(41)$ & $1(50)$ & $15(42)$ \\
\hline Mean (SE) & $9.0(1.6)$ & $15.5(15.5)$ & $9.4(1.6)$ \\
\hline
\end{tabular}

$H C V$ hepatitis $\mathrm{C}$ virus, OST opioid substitution therapy, $V L$ viral load

${ }^{a}$ Methadone category includes methadone, methadone hydrochloride and levomethadone hydrochloride

b Buprenorphine category includes buprenorphine, buprenorphine hydrochloride and buprenorphine with naloxone

c A score $\geq 8$ is associated with harmful or hazardous drinking

patients received $1125 \mathrm{mg}$ twice-daily telaprevir (oral). 93\% (43/46) of patients received Peg-IFN alfa $2 \mathrm{a}(180 \mu \mathrm{g} /$ week, subcutaneously) and $7 \%$ (3/46) received Peg-IFN alfa $2 \mathrm{~b}(100-150 \mu \mathrm{g} /$ week, subcutaneously). In addition, 96\% (44/ 46) received an initial oral RBV dose of 1000 or $1200 \mathrm{mg} / \mathrm{day}$, and $4 \%(2 / 46)$ received initial doses $\leq 800 \mathrm{mg} /$ day.

Patients included in the ITT population were mainly white $(91 \%)$, male $(87 \%)$ and $\leq 45$ years old $(61 \%)$. Most patients were infected with HCV GT1a (80\%), non-cirrhotic (85\%) and treatment-naïve (93\%). Of the patients, $74 \%$ were on OST during pre-treatment phase, and $91 \%$ during treatment phase, while $80 \%$ reported a history of heroin and/or cocaine use, of whom $22 \%$ had last used them in the previous month and $70 \%$ more than 6 months ago. Also, $37 \%$ of patients had an active concomitant psychiatric condition, mainly depression and anxiety (Table 1).

Of the total patients, $43 \%(20 / 46)$ discontinued treatment prematurely (Fig. 1). The two main reasons were loss to follow-up $(8 / 46 ; 17 \%)$ and adverse event (AE) $(6 / 46 ; 13 \%)$.
Overall, the SVR12 rate was 54\% (95\% CI 39, $69 ; 25 / 46)$ in the ITT population and $74 \%(95 \%$ CI 56,$87 ; 25 / 34$ ) in the EE population (Table 2). In the ITT population, 91\% (42/46) patients experienced at least one on-treatment $\mathrm{AE}$, and $24 \%(11 / 46)$ experienced one or more serious $\mathrm{AE}(\mathrm{s})$. The only serious $\mathrm{AE}$ occurring in more than one patient was anemia $(n=2)$. The most frequently reported AEs, occurring in more than $20 \%$ of patients in the ITT population, were anemia (39\%), thrombocytopenia (30\%), leukopenia $(30 \%)$, fatigue $(26 \%)$, and pruritus (22\%).

Mean adherence to telaprevir, Peg-IFN and RBV was $>91 \%$ at Weeks 4 and 12 among patients who responded to the M-MASRI questionnaire, and mean adherence to Peg-IFN/RBV was $>89 \%$ at end of treatment (Table 3). Adherence could not be measured by pill/vial count, as initially planned in the protocol, because most patients did not return their used medication packages.

Mean (SE) alcohol consumption score at baseline, as assessed by AUDIT questionnaire, was 9.4 (1.63). Alcohol consumption among 
Table 2 Summary of treatment outcomes

\begin{tabular}{lcl}
\hline $\begin{array}{l}\text { Treatment } \\
\text { outcome, } \boldsymbol{n}(\%)\end{array}$ & $\begin{array}{l}\text { ITT population, } \\
\boldsymbol{n}=\mathbf{4 6}\end{array}$ & $\begin{array}{l}\text { EE population, } \\
\boldsymbol{n}=\mathbf{3 4}\end{array}$ \\
\hline SVR12 & $25(54)$ & $25(74)$ \\
Relapse & $1(2)$ & $1(3)$ \\
Viral breakthrough & $1(2)$ & $1(3)$ \\
Other & $19(41)$ & $7(21)$ \\
\hline
\end{tabular}

ITT Intent-to-treat population. Ttreatment outcome Other $(n=19): 2$ had HCV RNA $>25 \mathrm{IU} / \mathrm{mL}$ at SVR time point but neither had a relapse nor viral breakthrough and 17 patients had missing data within the follow-up Week 12 window (8 lost to follow-up, 3 completed treatment but had no HCV RNA at SVR12 timepoint, 1 protocol violation, 1 consent withdrawal, 2 premature discontinuations due to AE, 2 Other

$E E$ Evaluable for effectiveness population, excluding patients lost to follow-up, patients who completed treatment but did not have HCV RNA assessment available at SVR12 time point, and patients with major protocol deviations plausibly affecting effectiveness; 12 patients were excluded from the EE population: 8 LTFU, 3 who completed treatment but had no HCV RNA available at SVR12 time point, and 1 who was a previous Null responder who received boceprevir instead of telaprevir (protocol violation). Treatment outcome Other $(n=7): 2$ patients had HCV RNA $>25 \mathrm{IU} / \mathrm{mL}$ at SVR12 time point but neither had a relapse nor viral breakthrough, 5 discontinued treatment prematurely ( 2 AEs, 1 patient withdrawal, 2 other) and had no HCV RNA available after discontinuation

patients in the ITT population decreased during the treatment phase (Week 12: 7.1; 1.57; Week $24: 7.1 ; 2.75)$.

\section{DISCUSSION}

Our prospective, observational study showed a SVR rate of 54\% (ITT population; 74\% EE population) in patients with a history of injecting drug use chronically infected with HCV genotype $1 \mathrm{HCV}$. Our findings were consistent with the virologic cure rates and safety profile of telaprevir combined with Peg-IFN/ribavirin obtained in a large HCV-TARGET real-world cohort [18].
Table 3 Adherence to treatment throughout the study period as determined by the M-MASRI questionnaire

Total

$(n=46)$

Telaprevir

Patients with adherence data at Week 4, 32

$n$

Mean (SD)

$95.6(7.80)$

Median (range)

$100(70,100)$

Patients with adherence data at Week

22

$12, n$

Mean (SD)

Median (range)

$100(50,100)$

Peg-IFN

Patients with adherence data at Week 4, 29

$n$

Mean (SD)

Median (range) $100(50,100)$

Patients with adherence data at Week

21

$12, n$

Mean (SD)

Median (range) $100(60,100)$

Patients with adherence data at EOT, $n 20$

Mean (SD)

Median (range)

$100(5,100)$

$\mathrm{RBV}$

Patients with adherence data at Week 4, 28

n

Mean (SD)

Median (range)

$100(70,100)$

Patients with adherence data at Week

18

$12, \mathrm{n}$

Mean (SD)

Median (range)

$100(30,100)$

Patients with adherence data at EOT, n 19

Mean (SD)

Median (range)

$100(5,100)$

$E O T$ end of treatment, $I F N$ interferon, $R B V$ ribavirin, $S D$ standard deviation 
Our results shed important light on the challenges associated with treating $\mathrm{HCV}$ in patients with a history of injecting drug use. The high rate of premature discontinuation, mainly due to loss to follow-up (17\%) and adverse events (13\%), is noteworthy. The complexity of the regimen, and its relatively poor safety profile (compared with IFN-free combination therapies), may have contributed to this high drop-out rate. However, patients who were lost to follow-up did not withdraw consent, but rather ceased to attend the study center for regular care.

Our study has several limitations. Firstly, recruitment was lower than expected owing to the extremely rapid evolution of hepatitis C treatments between 2011 and 2014 and the advent of IFN-free combination therapies, which now represent the standard-of-care in most regions. As a consequence of the superior efficacy and safety profiles of IFN-free combinations, IFN-based triple therapies such as the telaprevir and Peg-IFN/RBV combination are now obsolete. Secondly, compliance to treatment could only be measured by self-reported adherence as most patients did not bring back their packages to the institution, hindering the interpretation of our adherence data. However, the observed SVR rate in the EE population (74\%) suggests that on-treatment compliance was good, since it is similar to the $75 \%$ SVR rate obtained in the ADVANCE registrational clinical trial [9]. Our inability to perform pill/vial counts illustrates the challenges associated with the management of this patient population, reflecting real-world clinical practice, in contrast with the highly selected patients typically enrolled in interventional randomized controlled trials.

Post-hoc analyses of recent interventional clinical trials investigating IFN-free combinations have reported very high treatment completion and SVR rates (both $>90 \%$ ) in patients on OST $[19,20]$. The interventional C-EDGE CO-STAR study, which was conducted exclusively in patients on OST, confirmed these findings as only $3 \%(10 / 296)$ of patients were lost to follow-up during the 12-week post-treatment period. In contrast, 11-13\% loss-to-follow-up rates have been reported in some recent real-world studies conducted in PWIDs (on OST or not) treated with IFN-free combinations [21, 22].

One possible reason for this discrepancy in dropout rates relates to the stringent patient selection criteria typically applied in interventional trials, but less so in observational studies. For example, the C-EDGE CO-STAR study only enrolled patients on OST who had a documented compliance to appointments of at least $80 \%$ [12]. However, recent real-world studies have demonstrated that low loss-to-follow-up rates and high SVR rates (exceeding 90\%) can be achieved in PWIDs receiving integrated care from multidisciplinary teams $[23,24]$, and that rates of treatment completion and SVR comparable with the general patient population can be achieved in active drug users and patients receiving OST [25]. These findings support the provision of DAA therapy to such patients, the treatment of whom is key to achieving the goal of elimination of HCV transmission [25].

Strategies to improve adherence and boost continuity of care in PWIDs are essential if successful outcomes are to be achieved in these patient populations, not only to ensure that they are cured but also to prevent reinfection and minimize ongoing transmission [26]. Such strategies could include incentivizing patients, implementing directly-observed therapy or other individualized approaches.

\section{CONCLUSION}

Despite a substantial treatment discontinuation rate (including loss-to-follow-up), self-reported on-treatment adherence to telaprevir combined with Peg-IFN and ribavirin was high and virologic cure rates were similar to those seen in large real-world cohorts. This indicates that people with a history of injecting drugs should not be refused treatment and suggests that improving retention in care is necessary to facilitate appropriate medical follow-up. 


\section{ACKNOWLEDGEMENTS}

We thank the patients who participated in the study, study center staff and Janssen Pharmaceuticals personnel. This prospective, observational study and the article processing charges were sponsored by Janssen Pharmaceuticals. All authors had full access to all of the data in this study and take complete responsibility for the integrity of the data and accuracy of the data analysis. Medical writing support was provided by Stephanie Gibson and Ian Grieve (Zoetic Science, an Ashfield Company, part of UDG Healthcare, Macclesfield, UK) and Catherine Nalpas (employee of Janssen Pharmaceuticals) and was funded by Janssen Pharmaceuticals. All named authors meet the International Committee of Medical Journal Editors (ICMJE) criteria for authorship for this manuscript, take responsibility for the integrity of the work as a whole, and have given final approval to the version to be published.

Disclosures. Geert Robaeys has received research grants from Merck Sharp \& Dohme, AbbVie, Janssen Pharmaceuticals, and has acted as a scientific consultant for Gilead Sciences, Abbvie, Merck Sharp \& Dohme, Bristol Myers-Squibb. Stefan Christensen has acted as a scientific consultant and/or speaker for Abbvie, Bristol-Myers Squibb, Hexal, Janssen-Cilag, Merck Sharp \& Dohme, Reckitt-Benckiser, ViiV-Healthcare. Philip Bruggmann has received research/project grants from Janssen Pharmaceuticals, Gilead Sciences, AbbVie, Merck, Bristol Myers-Squibb, acted as a scientific consultant and/or speaker for Janssen Pharmaceuticals, Gilead Sciences, AbbVie, Merck, Bristol Myers-Squibb. Jan Kunkel has received consultancy fees from Gilead Sciences and conference attendance support from Gilead Sciences, Janssen Pharmaceuticals. Graham R. Foster has received research grants: from Roche, Gilead Sciences, Springbank, and has acted as a scientific consultant for AbbVie, Boehringer Ingelheim, Bristol Myers-Squibb, Roche, Gilead Sciences, Novartis, Merck, Janssen Pharmaceuticals. Chris Liu is a contractor for Janssen
Pharmaceuticals. Sophia Keim is an employee of Janssen Pharmaceuticals. Martin Jäkel is an employee of Janssen Pharmaceuticals. Ralph DeMasi is an employee of Janssen Pharmaceuticals. Isabelle Lonjon-Domanec is an employee of Janssen Pharmaceuticals. Damien Lucidarme and Amber Arain have nothing to disclose.

Compliance with Ethics Guidelines. The study was reviewed and approved by Independent Ethics Committees and conducted in accordance with the Helsinki Declaration of 1964, as revised in 2013, and Good Clinical Practice guidelines. All patients provided written, informed consent prior to the start of the study (clinicaltrials.gov NCT01980290).

Data Availability. The datasets during and/ or analyzed during the current study are available on reasonable request. Requests for access to datasets can be made via http://yoda.yale. edu/johnson-johnson.

Open Access. This article is distributed under the terms of the Creative Commons Attribution-NonCommercial 4.0 International License (http://creativecommons.org/licenses/ by-nc/4.0/), which permits any noncommercial use, distribution, and reproduction in any medium, provided you give appropriate credit to the original author(s) and the source, provide a link to the Creative Commons license, and indicate if changes were made.

\section{REFERENCES}

1. WHO hepatitis $\mathrm{C}$ fact sheet. Available at: http:// www.who.int/mediacentre/factsheets/fs164/en/. Accessed 7 Feb 2017.

2. Razavi H, Waked I, Sarrazin C, Myers RP, Idilman R, Calinas $\mathrm{F}$, et al. The present and future disease burden of hepatitis $\mathrm{C}$ virus (HCV) infection with today's treatment paradigm. J Viral Hepat. 2014;21(Suppl. 1):34-59.

3. Midgard H, Weir A, Palmateer N, Lo Re V 3rd, Pineda JA, Macías J, et al. HCV epidemiology in high-risk groups and the risk of reinfection. J Hepatol. 2016;65(Suppl 1):S33-45. 
4. Lanini S, Easterbrook PJ, Zumla A, Ippolito G. Hepatitis C: global epidemiology and strategies for control. Clin Microbiol Infect. 2016;22(10):833-8.

5. Cousien A. Hepatitis C treatment as prevention of viral transmission and liver-related morbidity in persons who inject drugs. Hepatology. 2016;63:1090-101.

6. Edlin BR, Kresina TF, Raymond DB, Carden MR, Gourevitch MN, Rich JD, et al. Overcoming barriers to prevention, care and treatment of hepatitis $\mathrm{C}$ in illicit drug users. Clin Infect Dis. 2005;40(Suppl. 5):S276-85.

7. Robaeys G, Van Vlierberghe H, Mathei C, Van Ranst M, Bruckers L, Buntinx F, et al. Similar compliance and effect of treatment in chronic hepatitis $\mathrm{C}$ resulting from intravenous drug use in comparison with other infection causes. Eur J Gastroenterol Hepatol. 2006;18:159-66.

8. Melin P, Chousterman M, Fontanges T, Ouzan D, Rotily M, Lang JP, et al. Effectiveness of chronic hepatitis $C$ treatment in drug users in routine clinical practice: results of a prospective cohort study. Eur J Gastroenterol Hepatol. 2010;22:1050-7.

9. Jacobson IM, McHutchinson JG, Dusheiko G, Di Bisceglie AM, Reddy KR, Bzowej NH, et al. Telaprevir for previously untreated chronic hepatitis $\mathrm{C}$ infection. N Engl J Med. 2011;364:2405-16.

10. Bacon BR, Gordon SC, Lawitz E, Marcellin P, Vierling JM, Zeuzem S, et al. Boceprevir for previously treated chronic HCV genotype 1 infection. N Engl J Med. 2011;364:1207-17.

11. Dillon JF, Lazarus JV, Razavi HA. Urgent action to fight hepatitis $\mathrm{C}$ in people who inject drugs in Europe. Hepatol Med Pol. 2016;1:2.

12. Dore GJ, Altice F, Litwin AH, Dalgard O, Gane EJ, Shibolet $\mathrm{O}$, et al. Elbasvir-grazoprevir to treat Hepatitis $C$ virus infection in persons receiving opioid agonist therapy: a randomized trial. Ann Intern Med. 2016;165:625-34.

13. Goodman ZD. Grading and staging systems for inflammation and fibrosis in chronic liver diseases. J Hepatol. 2007;47:598-607.

14. Martinez SM, Crespo G, Navasa M, Forns X. Noninvasive assessment of liver fibrosis. Hepatology. 2011;53:325-35.

15. Walsh JC, Mandalia S, Gazzard BG. Responses to a 1 month self-report on adherence to antiretroviral therapy are consistent with electronic data and virological treatment outcome. AIDS. 2002;16:269-77.
16. Babor TF, Higgins-Biddle JC, Saunders JB, Monteiro MG. AUDIT: The alcohol use disorders identification test, guidelines for use in primary care. Geneva: World Health Organization. Department of Mental Health and Substance Dependence; 2001.

17. Saunders JB, Aasland OG, Babor TF, de la Fuente JR, Grant M. Development of the alcohol use disorders identification test (AUDIT): WHO collaborative project on early detection of persons with harmful alcohol consumption II. Addiction. 1993;88:791-804.

18. Sterling RK, Kuo A, Rustgi VK, Sulkowski MS, Stewart TG, Fenkel JM, et al. Virologic outcomes and treatment algorithms utilization in observational study of patients with chronic hepatitis $C$ treated with boceprevir or telaprevir. Aliment Pharmacol Ther. 2015;41:671-85.

19. Grebely J, Dore GJ, Zeuzem S, Aspinall RJ, Fox R, Han L, et al. Efficacy and safety of sofosbuvir/velpatasvir in patients with chronic hepatitis $C$ virus infection receiving opioid substitution therapy: analysis of Phase 3 ASTRAL results. Clin Infect Dis. 2016;63:1479-81.

20. Grebely J, Mauss S, Brown A, Bronowicki J-P, Puoti $M$, Wyles D, et al. Efficacy and safety of ledipasvir/sofosbuvir with and without ribavirin in patients with chronic HCV Genotype 1 infection receiving opioid substitution therapy: analysis of phase 3 ION trials. Clin Infect Dis. 2016;63:1405-11.

21. Christensen S, Schober A, Mauss S, Busch H, Günther R, Teuber G, et al. DAA-treatment of HCV-infected patients on Opioid Substitution Therapy (OST): does the clinical setting matter? Data from the German Hepatitis C-Registry (DHC-R). AASLD Liver Meeting 2016. Boston, MA, November 11-15 2016. Abstract 1980.

22. Hull M, Gallagher L, Pare D, Kason D, Persaud S, Nouch S, et al. Real world outcomes of direct acting antiviral (DAA) therapy for hepatitis C (HCV) amongst persons who inject drugs treated in an inner-city hepatitis $\mathrm{C}$ treatment program, Vancouver, Canada. 2016. 5th International Symposium on Hepatitis Care in Substance Users. Available at: https://www.eiseverywhere.com/file_uploads/1a0a6 aab975530ed73e635f394654af3_139_MarkHull.pdf. Accessed 7 Feb 2017.

23. Alimohammadi A, Hakobyan S, Raycraft T, Vafadary S, Conway B. Evaluation of HCV treatment in people who actively inject drugs. Fut Virol. 2016;11:483-7.

24. Litwin AH, Agyemang L, Akiyama M, Heo M, Wong J, Soloway IJ, et al. High rates of sustained virological response in people who inject drugs treated 
with all-oral direct acting antiviral regimens. 5th International Symposium on Hepatitis Care in Substance Users. Available at: https://www.eisevery where.com/file_uploads/ec626d74ab97207d900dd c93eeb18144_166_AlainLitwin.pdf. Accessed 7 Feb 2017.

25. Bielen $\mathrm{R}$, Van Vlierberghe $\mathrm{H}$, Bourgeois $\mathrm{S}$, Moreno C, Vanwollegem T, Verlinden W, Mulkay JP, et al.
Belgian experience with direct acting antivirals in people who inject drugs. AASLD 2016:Abstract 910.

26. Norton BL, Beitin A, Glenn M, DeLuca J, Litwin AH, Cunningham CO. Retention in buprenorphine treatment is associated with improved HCV care outcomes. J Subst Abuse Treat. 2017;75:38-42. 